\title{
G4MP2, DFT and CBS-Q calculation of proton and electron affinities, gas phase basicities and ionization energies of hydroxylamines and alkanolamines
}

\author{
YOUNES VALADBEIGI, HOSSEIN FARROKHPOUR* and MAHMOUD TABRIZCHI \\ Department of Chemistry, Isfahan University of Technology, Isfahan, 84156-83111, Iran \\ e-mail: farrokhphossein@gmail.com
}

MS received 26 October 2013; revised 3 April 2014; accepted 6 April 2014

\begin{abstract}
The proton affinities, gas phase basicities and adiabatic ionization energies and electron affinities of some important hydroxylamines and alkanolamines were calculated using B3LYP, CBS-Q and G4MP2 methods. Also, the B3LYP method was used to calculate vertical ionization energies and electron affinities of the molecules. The calculated ionization energies are in the range of 8-10.5 eV and they decrease as the number of carbon atoms increases. Computational results and ion mobility spectrometry study confirm that some alkanolamines lose a water molecule due to protonation at oxygen site and form cationic cyclic compounds. Effect of different substitutions on the cyclization of ethanolamine was studied theoretically.
\end{abstract}

Keywords. Alkanolamines; computational methods; proton affinity; heterocyclic compounds; ion mobility spectrometry.

\section{Introduction}

Proton transfer reactions and ionization are important processes that play a key role in the atmospheric chemistry and biochemistry. ${ }^{1,2}$ Proton affinity and gas phase basicity determine the capability of an atom or a molecule to accept a proton in the gas phase. The proton affinity, PA, of a molecule, $\mathrm{M}$, is defined as $-\Delta \mathrm{H}$ of its protonation in the gas phase,

$$
\mathrm{M}(\mathrm{g})+\mathrm{H}^{+}(\mathrm{g}) \rightarrow \mathrm{MH}^{+}(\mathrm{g})
$$

Also, gas phase basicity of $\mathrm{M}$ is defined as the Gibbs free energy change $(-\Delta G)$ of reaction (1). Proton affinity and gas phase basicity of compounds are determined using different experimental techniques. ${ }^{3,4}$ For example, proton affinity of $\mathrm{M}$ is measured by mass and ion mobility spectrometry (IMS) from the following proton-exchange reaction in the gas phase. ${ }^{3}$

$$
\mathrm{M}(\mathrm{g})+\mathrm{NH}^{+}(\mathrm{g}) \rightarrow \mathrm{MH}^{+}(\mathrm{g})+\mathrm{N} .
$$

However, since experimental measurement of the proton affinity is not easy, recently there has been much interest in computational methods to determine the proton affinity. ${ }^{5-7}$

Adiabatic ionization energy (AIE) and adiabatic electron affinity (AEA) are the energy difference between

\footnotetext{
*For correspondence
}

neutral molecule and its cation and anion when all species are in their ground electronic states, respectively. ${ }^{8}$ The electronic energy difference between the ground states of the neutral molecule and its anion or cation at the equilibrium geometry of the neutral molecule is called the vertical electron affinity (VEA) and ionization energy (VIE) respectively. ${ }^{8}$ Ionization energy and electron affinity are useful quantities for Chemists and Biochemists, because these properties help to understand the chemical and biological phenomena like electron donor and acceptor abilities of DNA. ${ }^{9}$

Hydroxylamines and alkanolamines are important compounds which have high applications in organic and inorganic synthesis and need special care for preparations. ${ }^{10,11}$ Hydroxylamines can be used to produce amines ${ }^{10}$ and they react with aldehydes and ketones to form oximes. ${ }^{12}$ Alkanolamines such as ethanolamine (EA) and diethanolamine (DEA) are base chemicals in the production of pharmaceuticals, detergents, emulsifiers, polishes, corrosion inhibitors and chemical intermediates. ${ }^{11}$ DEA is used to synthesize morpholine, an important heterocyclic molecule. ${ }^{13}$

The hydroxylamines and alkanolamines have two different sites, oxygen and nitrogen atoms, to accept a proton. Hence, they have two different values for the proton affinity and gas phase basicity. Protonation of molecules with different proton acceptor sites have been studied both experimentally and theoretically. ${ }^{4,7,14}$ 
These studies show that nitrogen atom is the preferential site of protonation. ${ }^{7,14}$

Ionization energies of some alkanolamines and hydroxylamines have been determined experimentally using photoelectron and ionization spectroscopy. ${ }^{15-18}$ The experimental ionization energies for hydroxylamine, N-methyl, hydroxylamine, O-methyl, hydroxylamine and DEA are 9.6, 9.82, 10.28 and $9.87 \mathrm{eV}$, respectively. ${ }^{15-18}$ In this work, the proton affinities, gas phase basicities, both adiabatic and vertical ionization energies and electron affinities of hydroxylamine, $\mathrm{N}$ methyl-hydroxylamine, O-methyl-hydroxylamine, methanolamine, dimethanolamine, trimethanolamine, EA and DEA are calculated using G4MP2, B3LYP/6$311++\mathrm{G}(2 \mathrm{df}, \mathrm{p})$ and CBS-Q computational methods.

\section{Experimental and Computational Details}

G4MP2, B3LYP and CBS-Q computational methods are commonly used to calculate the thermodynamic properties of compounds. ${ }^{6}$ It is shown that density functional theory (DFT) methods with a large and reasonable basis set can give reliable thermodynamic properties for systems included hydrogen bonding, ${ }^{19,20}$ therefore, the B3LYP as a DFT method was selected in this work. Large basis set, 6-311++G(2df,p), used for the DFT calculations which involves polarization and diffuse functions for both hydrogen and heavy atoms.

Compound methods such as complete basis set $(\mathrm{CBS})^{21}$ and Gaussian methods (G1-G4) $)^{22,23}$ are known as good methods to accurately compute thermodynamic properties. In the CBS-Q and G4MP2, the total energy is computed from a series of consecutive calculations. In the CBS-Q method the MP2 is used for geometry optimization and a complete basis set extrapolation of the correlation energy and then corrected to the $\operatorname{CCSD}(\mathrm{T})$ level by adding some corrections. ${ }^{20}$ In G4 method, the optimized structure and zero point energy are obtained at the B3LYP/6-31G(2df,p) level of theory. ${ }^{22}$ Then, a series of single point correlation energy calculations are performed at the MP4/631G(d), MP4/6-31+G(d), CCSD(T)/6-31G(d), MP2 and MP3 levels of theory. These energies are modified by some corrections at the end. ${ }^{22}$ In the G4(MP2) theory calculations by the MP3 and MP4 methods with large basis set are eliminated. ${ }^{23}$ It is found that G4(MP2) is more accurate than G3 method. ${ }^{23}$ All calculations were performed using Gaussian 09 quantum chemistry package. ${ }^{24}$

Figure 1 shows the schematic diagram of the ion mobility spectrometer (IMS) used in this work. The detail components of the IMS have been explained in the reference section. ${ }^{25}$ In summary, the sample is ionized with a corona discharge in the ionization region of IMS. The drift gas (pure nitrogen, 99.999\%) is used to prevent the entrance of neutral species into the drift tube, therefore, only protonated molecules enter into the drift tube. The flow rates of the drift and the carrier gas were typically $900 \mathrm{~mL} / \mathrm{min}$ and, $500 \mathrm{~mL} / \mathrm{min}$, respectively. The identities of the ions are then determined by measuring their mobility in an electric field. Diethanolamine (DEA) used in this work was a Merck product of analytical grade and was $99.9 \%$ pure.

\section{Results and discussion}

Figure 2 shows the optimum structures of hydroxylamine, N-methyl-hydroxylamine, O-methyl- hydroxylamine, methanolamine, dimethanolamine, trimethanolamine, ethanolamine and DEA optimized at the B3LYP level of theory using 6-311++G(2df,p) basis set. To compute the proton affinities, gas phase basicities, ionization energies and electron affinities of the mentioned molecules, it is necessary to perform the calculation on the protonated molecules, their cations and anions.

The proton affinity values were obtained by calculating the change of enthalpy for reaction (1), where $\mathrm{M}$ presents the amine. The enthalpy of $\mathrm{H}^{+}$was computed as 0.00236 Hartree which equals $5 / 2 R T$. Table 1 presents proton affinities of the molecules calculated at G4MP2, B3LYP and CBS-Q levels of theory. All of the molecules can be protonated via both nitrogen $(\mathrm{N})$ and oxygen $(\mathrm{O})$ centers. In the tables 1 and 2 the atoms shown in parenthesis, $\mathrm{N}$ and $\mathrm{O}$, indicate that the molecule is protonated from the nitrogen $(\mathrm{N})$ or oxygen $(\mathrm{O})$ sites. For the most of the molecules, nitrogen atoms are preferential sites for protonation, except in the case of trimethanolamine whose three methanol groups do not allow the nitrogen atom to accept a proton easily. It seems, spatial structure of trimethanolamine, protonated from its nitrogen atom, makes it unstable. Table 1 shows that the calculated proton affinities using G4MP2, B3LYP and CBS-Q methods are in good agreement with each other and those reported in literature. ${ }^{26}$

The calculated gas phase basicities of the hydroxylamines and alkanolamines are tabulated in table 2 . The gas phase basicities of the molecules protonated from the nitrogen centers are more than those of the molecules protonated from oxygen atoms. The proton affinities and gas phase basicities reported in literature ${ }^{26}$ are in agreement with those calculated for 


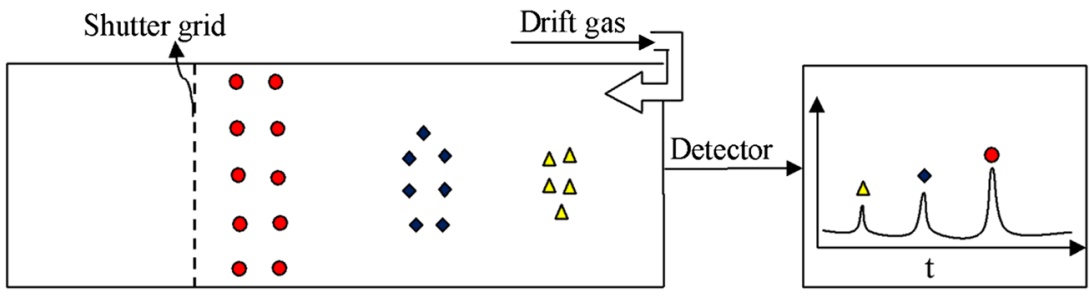

Ionization Region

Drift Tube

Figure 1. Schematic diagram of ion mobility spectrometer used in this work.

(a)

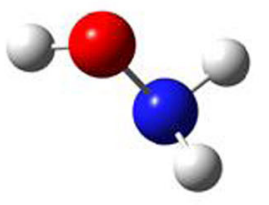

(e)

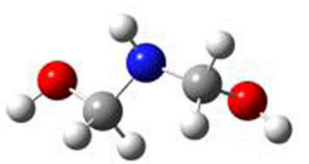

(b)

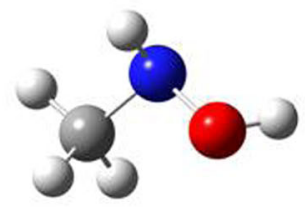

(f)

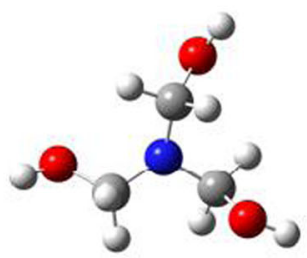

(c)

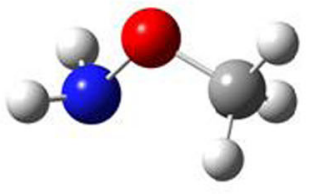

(g) (d)

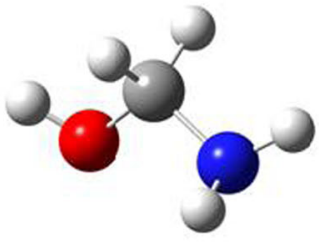

(h)

Figure 2. Optimum structures of hydroxylamine, N-methyl-hydroxylamine, O-methylhydroxylamine, methanolamine, dimethanolamine, trimethanolamine, EA and DEA optimized using B3LYP/6-311++G(2df,p).

Table 1. Calculated proton affinities ( $-\Delta \mathrm{H}$ of protonation) of the hydroxylamines and alkanolamines. Atoms in parenthesis are the protonation sites.

\begin{tabular}{|c|c|c|c|c|}
\hline Molecules & G4MP2 (kJ/mol) & CBS-Q (kJ/mol) & B3LYP* $(\mathrm{kJ} / \mathrm{mol})$ & Literature $(\mathrm{kJ} / \mathrm{mol})$ \\
\hline Hydroxylamine (N) & 817.61 & 814.67 & 810.84 & \\
\hline Hydroxylamine $(\mathrm{O})$ & 710.02 & 703.88 & 705.20 & \\
\hline $\mathrm{N}$-methyl-hydroxylamine (N) & 860.50 & 859.21 & 855.02 & \\
\hline N-methyl-hydroxylamine $(\mathrm{O})$ & 740.99 & 735.62 & 741.30 & \\
\hline O-methyl-hydroxylamine (N) & 847.48 & 844.09 & 843.12 & $844.8^{\mathrm{a}}$ \\
\hline O-methyl-hydroxylamine $(\mathrm{O})$ & 758.83 & 753.10 & 753.97 & \\
\hline Methanolamine $(\mathrm{N})$ & 897.22 & 896.43 & 895.16 & \\
\hline Methanolamine (O) & 885.09 & 889.96 & 893.99 & \\
\hline Dimethanolamine $(\mathrm{N})$ & 930.04 & 910.76 & 925.03 & \\
\hline Dimethanolamine $(\mathrm{O})$ & 929.03 & 910.83 & 933.50 & \\
\hline Trimethanolamine (N) & 940.56 & 937.28 & 932.06 & \\
\hline Trimethanolamine $(\mathrm{O})$ & 934.13 & 933.28 & 936.38 & \\
\hline Ethanolamine $(\mathrm{N})$ & 927.55 & 926.86 & 924.70 & $930.3^{\mathrm{a}}$ \\
\hline Ethanolamine $(\mathrm{O})$ & 774.48 & 770.25 & 776.80 & \\
\hline Diethanolamine (N) & 954.75 & 952.17 & 951.11 & $953^{\mathrm{a}}$ \\
\hline Diethanolamine $(\mathrm{O})$ & 919.37 & 917.82 & 908.46 & \\
\hline
\end{tabular}

*basis set: $6-311++\mathrm{G}(2 \mathrm{df}, \mathrm{p})$

${ }^{a}$ Ref. ${ }^{26}$ 
Table 2. Calculated gas phase basicities ( $-\Delta \mathrm{G}$ of protonation) of the hydroxylamines and alkanolamines. Atoms in parenthesis are the protonation sites.

\begin{tabular}{lcccc}
\hline Molecules & G4MP2 $(\mathrm{kJ} / \mathrm{mol})$ & $\mathrm{CBS}-\mathrm{Q}(\mathrm{kJ} / \mathrm{mol})$ & B3LYP* $(\mathrm{kJ} / \mathrm{mol})$ & Literature $(\mathrm{kJ} / \mathrm{mol})$ \\
\hline Hydroxylamine (N) & 786.16 & 783.44 & 779.65 & \\
Hydroxylamine (O) & 679.23 & 673.22 & 674.45 & \\
N-methyl-hydroxylamine (N) & 828.89 & 827.62 & 823.58 & \\
N-methyl-hydroxylamine (O) & 710.99 & 705.33 & 711.20 & $812.3^{\mathrm{a}}$ \\
O-methyl-hydroxylamine (N) & 814.67 & 811.86 & 810.91 & \\
O-methyl-hydroxylamine (O) & 727.15 & 722.35 & 722.57 & \\
Methanolamine (N) & 865.14 & 864.83 & 860.27 & \\
Methanolamine (O) & 863.58 & 865.03 & 867.96 & \\
Dimethanolamine (N) & 898.68 & 877.25 & 891.98 & \\
Dimethanolamine (O) & 905.82 & 890.26 & 910.97 & $896.8^{\mathrm{a}}$ \\
Trimethanolamine (N) & 907.61 & 905.18 & 898.25 & $920^{\mathrm{a}}$ \\
Trimethanolamine (O) & 913.29 & 915.71 & 916.87 & \\
Ethanolamine (N) & 894.69 & 894.63 & 892.10 & \\
Ethanolamine (O) & 747.58 & 745.42 & 749.51 & \\
Diethanolamine (N) & 923.36 & 920.50 & 919.48 & \\
Diethanolamine (O) & 893.55 & 896.96 & 884.91 & \\
\hline
\end{tabular}

*basis set: $6-311++\mathrm{G}(2 \mathrm{df}, \mathrm{p})$

${ }^{a} \operatorname{Ref}^{26}$

the molecules protonated from nitrogen atoms. In addition, the proton affinities and gas phase basicities increase as the number of carbon atoms increases. Since alkyl chain is electron donor, increasing of the number of the carbon atoms or the alkyl chain length make the molecule more capable to accommodate a positive charge. ${ }^{6}$ Table 2 shows that the calculated gas phase basicities using G4MP2, B3LYP and CBS-Q methods are in good agreement with those reported in literature. Since the computed values are in good agreement to those reported previously, it is expected that the computed proton affinity and gas phase basicity quantities for hydroxylamine, N-methylhydroxylamine, methanolamine, dimethanolamine and trimethanolamine, which have been not reported already, are reliable.

Figure 3 shows the optimum structures of (a) neutral, (b) $\mathrm{N}$ - and (c) O-protonated forms of methanolamine optimized by G4MP2 method. The $\mathrm{C}-\mathrm{O}$ and $\mathrm{C}-\mathrm{N}$ bond lengths of the three structures have been shown and compared in figure 3 . As seen, a water molecule is separated from the protonated methanolamine when the oxygen atom of this molecule accepts a proton. This phenomenon probably is one of the reasons for this fact that proton affinities of the molecules decrease when they are protonated from the oxygen sites; it so happens because bond breakage is an endothermic reaction.

The adiabatic ionization energies (AIE) were calculated using G4MP2, B3LYP and CBS-Q computational methods and the vertical ionization energies (VIE) were calculated at B3LYP level of theory using 6-311++G(2df,p) basis set. The calculated VIE and AIE values are tabulated in table 3 . Fifth column of the table 3 shows the reported ionization energy values in the literature. ${ }^{15-18,27-29}$ The results of calculations show that the VIE values are more than the AIEs. Some of the (a)

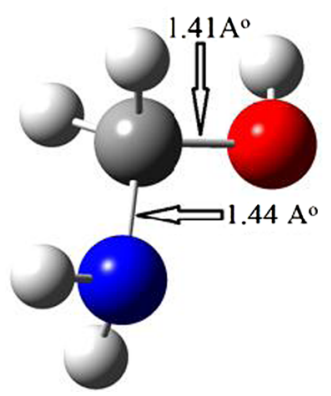

(b)

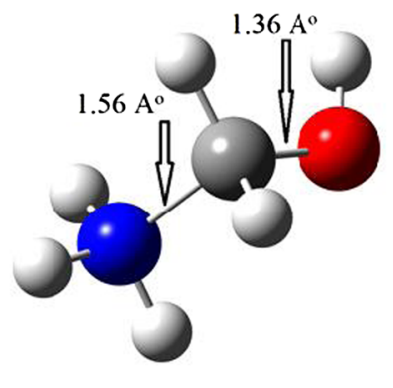

(c)

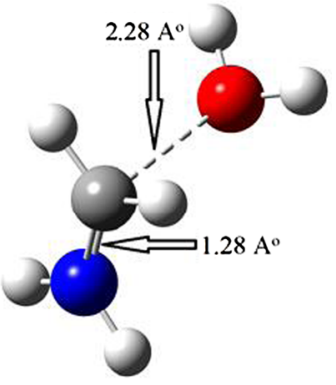

Figure 3. Optimum structures of (a) neutral, (b) N- and (c) O-protonated forms of methanolamine optimized by G4MP2 method. 
Table 3. Calculated vertical (VIE) and adiabatic ionization energies (AIE) of the hydroxylamines and alkanolamine. The units are in electron volt $(\mathrm{eV})$.

\begin{tabular}{|c|c|c|c|c|c|}
\hline Molecules & G4MP2 (AIE) & CBS-Q (AIE) & B3LYP* (AIE) & B3LYP* (VIE) & literature \\
\hline Hydroxylamine & 9.24 & 9.22 & 9.12 & 10.61 & $\begin{array}{c}9.6^{\mathrm{a}} \\
10.64^{\mathrm{b}}\end{array}$ \\
\hline N-methyl-hydroxylamine & 8.58 & 8.57 & 8.41 & 9.62 & $\begin{array}{l}9.0^{\mathrm{b}} \\
9.82^{\mathrm{b}}\end{array}$ \\
\hline O-methyl-hydroxylamine & 8.67 & 8.67 & 8.51 & 10.31 & $\begin{array}{r}9.55^{\mathrm{c}} \\
10.28^{\mathrm{d}}\end{array}$ \\
\hline Methanolamine & 9.12 & 9.16 & 8.87 & 9.53 & \\
\hline Dimethanolamine & 8.37 & 8.63 & 8.16 & 8.93 & \\
\hline Trimethanolamine & 8.04 & 8.14 & 7.86 & 8.69 & \\
\hline Ethanolamine & 8.82 & 8.78 & 8.54 & 9.23 & $\begin{array}{l}8.9^{\mathrm{e}} \\
8.96^{\mathrm{f}} \\
9.87^{\mathrm{g}}\end{array}$ \\
\hline Diethanolamine & 8.03 & 8.11 & 7.79 & 8.52 & \\
\hline
\end{tabular}

*basis set: $6-311++\mathrm{G}(2 \mathrm{df}, \mathrm{p})$

${ }^{\text {a }}$ Ref. ${ }^{15}$, ${ }^{\text {b }}$ Ref. ${ }^{16}$, ${ }^{\mathrm{c}}$ Ref. ${ }^{27}$, ${ }^{\mathrm{d}}$ Ref. ${ }^{17}$, ${ }^{\mathrm{e}}$ Ref. ${ }^{28}$, ${ }^{\mathrm{f}}$ Ref. ${ }^{29}$, ${ }^{\mathrm{g}}$ Ref. ${ }^{18}$.

experimental ionization energies reported in table 3 are in agreement with the VIEs and others with the AIEs values. The calculated AIE and VIE values decrease as the number of carbon atoms increases. For example, the adiabatic ionization energies of methanolamine, dimethanolamine and trimethanolamine calculated by the B3LYP are 8.87, 8.16 and 7.86 eV, respectively.

Table 4 shows the calculated adiabatic (AEA) and vertical electron affinities (VEA) of the hydroxylamines and alkanolamines. The electron affinity values obtained by the B3LYP and G4MP2 methods have good consistency in the case of hydroxylamines, O-methylhydroxylamine and $\mathrm{N}$-methyl-hydroxylamine while the ionization energy values of alkanolamines calculated using CBS-Q and G4MP2 methods are in agreement with each other. However, these three methods show the same electron affinity trend so that electron affinities increase as the number of carbon atoms increases. In other words, accommodation of an electron by a large alkanolamine is easier than by a small one. The B3LYP method was used to calculate both AEA and VEA values. Comparison of the AEA and VEA values shows that they are the same in the case of hydroxylamine, $\mathrm{N}$ methyl-hydroxylamine and O-methyl-hydroxylamine while for the alkanolamines the VEA values are more negative.

The computational results show that the DEA produce heterocyclic compound due to protonation from the oxygen site by losing a water molecule. Figure $4 \mathrm{a}$ shows the optimum structure of DEA that is protonated from oxygen atom optimized at G4MP2 level of theory. The same cyclic structure obtained when the O-protonated DEA was optimized by the B3LYP and CBS-Q methods. Protonation of ethanoamine does not result in cyclic compound, although a water molecule separates from it (figure 4b). When an oxygen atom of (di)ethanolamine accepts a proton, a water molecule separates from it and its carbon atom accepts a positive charge. In case of DEA, accommodation of the positive charge by the nitrogen atom, which is

Table 4. Calculated vertical (VEA) and adiabatic electron affinities (VEA) of the hydroxylamines and alkanolamine. The units are in electron volt $(\mathrm{eV})$.

\begin{tabular}{lcccc}
\hline Molecules & G4MP2 (AEA) & CBS-Q (AEA) & B3LYP* (AEA) & B3LYP* (VEA) \\
\hline Hydroxylamine & -0.31 & -2.62 & -0.72 & -0.73 \\
N-methyl-hydroxylamine & -0.22 & -2.51 & -0.62 & -0.61 \\
O-methyl-hydroxylamine & -0.29 & -0.14 & -0.62 & -0.63 \\
Methanolamine & -2.02 & -2.48 & -0.39 & -0.47 \\
Dimethanolamine & -1.44 & -1.52 & -0.13 & -0.40 \\
Trimethanolamine & -1.22 & -1.23 & +0.03 & -0.32 \\
Ethanolamine & -2.18 & -2.24 & -0.48 & -0.51 \\
Diethanolamine & -1.91 & -2.04 & -0.40 & -0.41 \\
\hline
\end{tabular}

*basis set: $6-311++\mathrm{G}(2 \mathrm{df}, \mathrm{p})$ 
(a)

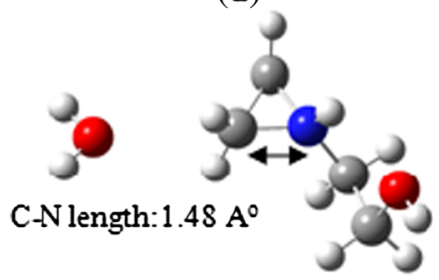

(c)

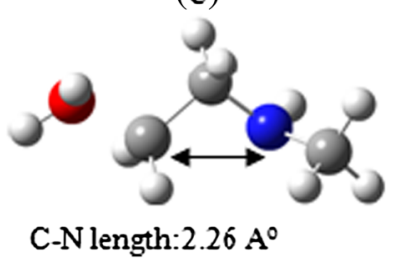

(b)

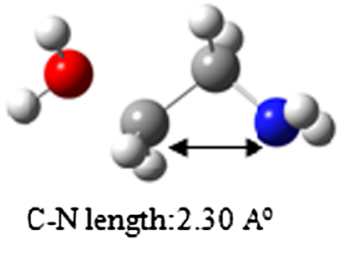

(d)

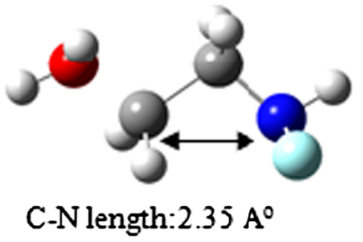

Figure 4. Optimum structures of (a) DEA, (b) EA, (c) Nmethyl-EA and (d) N-fluoro-EA protonated from oxygen site optimized using G4MP2 method.

connected to electron donor groups (ethyl or ethanol), is easier than the carbon atom. Therefore, the carbon and nitrogen atoms form a bond between themselves and the nitrogen atom is positively charged. The nitrogen atom of EA cannot easily accommodate a positive charge and its O-protonated form loses only a water molecule and does not produce a cyclic compound. To investigate the effect of electron donor/acceptor groups on the cyclization of EA, protonation of $\mathrm{N}$ methyl-EA and N-fluoro-EA was studied. Figures $4 \mathrm{c}$ and $4 \mathrm{~d}$ show the optimum structures of these two compounds which are protonated from the oxygen atoms. When an amine hydrogen is replaced with an electron donor group, C-N bond length decreases and the cyclization process becomes more favorable (figure 4).

Figure 5 shows ion mobility spectra of DEA as a function of temperature. Ionization mechanism in IMS is based on proton transfer from reactant ions such as $\mathrm{H}_{3} \mathrm{O}^{+}$to a molecule, $\mathrm{M}$,

$$
\mathrm{H}_{3} \mathrm{O}^{+}+\mathrm{M} \rightarrow \mathrm{MH}^{+}+\mathrm{H}_{2} \mathrm{O}
$$

DEA is protonated from two site in ionization region of IMS

$$
\begin{aligned}
& \mathrm{H}_{3} \mathrm{O}^{+}+\text {DEA } \rightarrow(\text { DEA })-\mathrm{NH}^{+}+\mathrm{H}_{2} \mathrm{O} \\
& \mathrm{H}_{3} \mathrm{O}^{+}+\text {DEA } \rightarrow(\text { DEA })-\mathrm{OH}^{+}+\mathrm{H}_{2} \mathrm{O}
\end{aligned}
$$

Where (DEA)- $\mathrm{NH}^{+}$and (DEA)- $\mathrm{OH}^{+}$are di-ethanolamine protonated from the nitrogen and oxygen sites, respectively. Since protonation of DEA from oxygen site results in separation of a water molecule from EDA, this positive ion has a mass and size less that the DEA

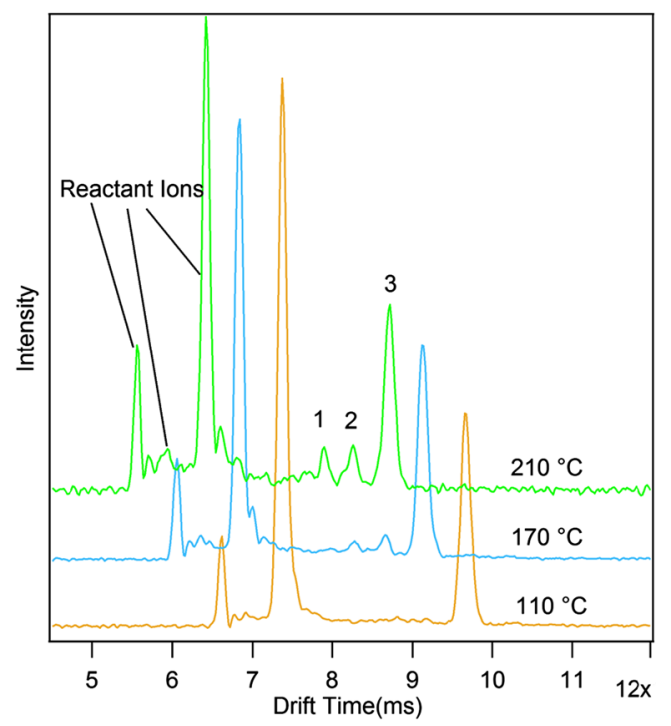

Figure 5. Ion mobility spectra of DEA at different temperatures.

protonated from nitrogen site. Therefore, it is expected that EDA has two peaks and the peak of EDA protonated from nitrogen site appear at higher drift time. Only one peak was observed (peak 3 ) at low temperature $\left(<100^{\circ} \mathrm{C}\right)$. As the temperature increased, two peaks appeared at lower drift times (peaks 1,2). Since protonation of EDA from $\mathrm{N}$ site is thermodynamically more favorable (tables 1 and 2) and this ion has higher mass and size, it is concluded that the observed peak at lower temperature and higher drift time (peak 3) is pertinent to this compound. As the temperature increases, protonation of DEA from the oxygen atom can take place. Two peaks were observed at higher temperature and lower drift times (peaks 1,2). One of the two peaks may be related to acyclic isomer of DEA protonated from oxygen site, and another is its cyclic form with the same mass. Mass spectrometry cannot distinguish two isomers of a molecule with the same mass while IMS has this ability. ${ }^{14}$ However, we cannot exactly assign the peaks in IMS, and peaks 1,2 may be related to other fragments of EDA molecule. To determine the identity of the observed peaks an IMS-MS is required.

\section{Conclusion}

The proton affinities, gas phase basicties and adiabatic and vertical ionization energies of the hydroxylamines and alkanolamines computed at the B3LYP, CBS-Q and G4MP2 levels of theory have good consistency with each other and with experimental data. As the number of carbon atoms increases the proton affinity, gas 
phase basicity and electron affinity values increase and ionization energies decrease. The calculated VEA and AEA values of hydroxylamines are almost the same but for the alkanolamines, the VEA values are more negative than AEV values. Protonation of alkanolamines at oxygen site can be used as a synthetic method for direct production of the heterocyclic compounds. To obtain higher heterocyclic compound yield, the nitrogen atom of alkanolamines should have electron donor groups and the cyclization reaction be done at higher temperatures.

\section{References}

1. Biot C, Wintjens R and Rooman M 2004 J. Am. Chem. Soc. 1266220

2. Zhao J and Zhang R 2004 Atmos. Environ. 382177

3. Tabrizchi M and Shooshtari S 2003 J. Chem. Thermodynamics 35863

4. da Silava E F 2005 J. Phys. Chem. A 1091603

5. Namazian M and Coote M L 2008 J. Chem. Thermodynamics $\mathbf{4 0} 1116$

6. Valadbeigi Y and Farrokhpour H 2013 Int. J. Quantum Chem. 1131717

7. Perez P and Contreras R 1998 Chem. Phys. Lett. 293 239

8. Rienstra- Kiracofe C J, Tschumper G S and Schaefer H F 2002 Chem. Rev. 102231

9. Roca-Sanjuán D, Merchán M, Serrano-Andrés L and Rubio M 2008 J. Chem. Phys. 1290951041

10. March S and Jerry M 2001 March's advanced organic chemistry: Reactions, mechanisms, and structure (New York: Wiley) p. 1554

11. Weissermel K, Arpe H J, Lindley C R and Hawkins S 2003 Oxidation products of ethylene. Industrial organic chemistry (New York: Wiley-VCH)

12. Shriner R L, Fuson R C and Curtin D Y 1964 The systematic identification of organic compounds: A laboratory manual, 5th ed. (New York: Wiley). Chapter 6

13. Frauenkron M, Johann-Peter M, Ruider G, Rossbacher R and Höke H 2002 Ethanolamines and Propanolamines In Ullmann's Encyclopedia of Industrial Chemistry (New York: Wiley-VCH)

14. Bahrami H, Tabrizchi M and Farrokhpour H 2013 Chem. Phys. 415222
15. Kutina R E, Goodman G L and Berkowitz J $1982 \mathrm{~J}$. Chem. Phys. 771664

16. Rademacher P and Freckmann B 1980 J. Electron Spectrosc. Relat. Phenom. 19251

17. Kimura K and Katsumata S 1977 J. Chem. Phys. 67 1225

18. Leavell S, Steichen J and Franklin J L 1973 J. Chem. Phys. 594343

19. Wei D Q and Salahub D R 1998 In Combined Quantum Mechanical and Molecular Mechanical Methods (eds.) J Gao and M Thompson (New York: Wiley) Chapter 1115

20. Wei D Q, Proynov E I, Milet A and Salahub D R 2000 J. Phys. Chem. 1042384

21. Montgomery A, Frisch M J, Ochterski J W and Petersson G A 2000 J. Chem. Phys. 1126532

22. Curtiss L A, Redfern P C and Raghavchari K 2007 J. Chem. Phys. 126 084108-1

23. Curtiss L A, Redfern P C and Raghavchari K $2007 \mathrm{~J}$. Chem. Phys. 127 124105-1

24. Frisch M J, Trucks G W, Schlegel H B, Scuseria G E, Robb M A, Cheeseman J R, Scalmani G, Barone V, Mennucci B, Petersson G A, Nakatsuji H, Caricato M, Li X, Hratchian H P, Izmaylov A F, Bloino J, Zheng G, Sonnenberg J L, Hada M, Ehara M, Toyota K, Fukuda R, Hasegawa J, Ishida M, Nakajima T, Honda Y, Kitao O, Nakai H, Vreven T, Montgomery J A Jr., Peralta J E, Ogliaro F, Bearpark M, Heyd J J, Brothers E, Kudin K N, Staroverov V N, Kobayashi R, Normand J, Raghavachari K, Rendell A, Burant J C, Iyengar S S, Tomasi J, Cossi M, Rega N, Millam J M, Klene M, Knox J E, Cross J B, Bakken V, Adamo C, Jaramillo J, Gomperts R, Stratmann R E, Yazyev O, Austin A J, Cammi R, Pomelli C, Ochterski J W, Martin R L, Morokuma K, Zakrzewski V G, Voth G A, Salvador P, Dannenberg J J, Dapprich S, Daniels A D, Farkas O, Foresman J B, Ortiz J V, Cioslowski J and Fox D J 2009 Gaussian 09, Revision A.1. Gaussian, Inc., Wallingford

25. Valadbeigi Y and Tabrizchi M 2014 Int. J. Ion Mobil. Spect. 1735

26. Hunter E P L and Lias S G 1998 J. Phys. Chem. Ref. Data 27413

27. Molder U H, Pikver R J and Koppel I A 1983 Org. React. Tartu 20208

28. Ohno K, Imai K and Harada Y 1985 J. Am. Chem. Soc. 1078078

29. Molder U H, Pikver R J and Koppel I A 1983 Org. React. Tartu 20355 